\title{
Erratum to the role of postoperative radiotherapy for thymomas: a multicentric retrospective evaluation from three Italian centers and review of the literature
}

\author{
Editorial Office \\ Journal of Thoracic Disease \\ Correspondence to: Editorial Office. Journal of Thoracic Disease. Email: jtd@amepc.org.
}

doi: 10.21037/jtd-2021-04

View this article at: http://dx.doi.org/10.21037/jtd-2021-04

Erratum to: J Thorac Dis 2020;12:7518-30

This article that appeared on Page: 7518-7530, Vol 12, No 12 (December 2020) Issue of the Fournal of Thoracic Disease (FTD) (1), the authors' affiliations were published incorrectly. The affiliations should be corrected as follows:

Alessio Bruni ${ }^{1}$, Alessandro Stefani ${ }^{2}$, Marco Perna ${ }^{3}$, Paolo Borghetti ${ }^{4}$, Niccolò Giaj Levra $^{5}$, Elisa D’Angelo ${ }^{1}$, Alessandra D’Onofrio ${ }^{4}$, Laura Rubino ${ }^{1}$, Luca Frassinelli ${ }^{1}$, Viola Salvestrini ${ }^{3}$, Matteo Mariotti ${ }^{3}$, Filippo Alongi ${ }^{4,5}$, Alessandro Gonfiotti ${ }^{6}$, Lorenzo Livi ${ }^{3}$, Vieri Scotti ${ }^{3}$

${ }^{1}$ Radiotherapy Unit, Hematology and Oncology Department, University Hospital of Modena, Modena, Italy; ${ }^{2}$ Division of Thoracic Surgery, Department of Medical and Surgical Sciences for Children \& Adults, University of Modena and Reggio Emilia, Modena, Italy; ${ }^{3}$ Department of Radiation Oncology, Azienda Ospedaliero Universitaria Careggi, University of Florence, Florence, Italy; ${ }^{4}$ Department of Radiation Oncology, Spedali Civili of Brescia, Brescia, Italy; ${ }^{5}$ Department of Radiation Oncology, IRCCS Sacro Cuore Don Calabria Hospital, Negrar, Verona, Italy; ${ }^{6}$ Thoracic Surgery Unit, Azienda Ospedaliero Universitaria Careggi, Florence, Italy

Click here to view the updated version of the article.

Open Access Statement: This is an Open Access article distributed in accordance with the Creative Commons AttributionNonCommercial-NoDerivs 4.0 International License (CC BY-NC-ND 4.0), which permits the non-commercial replication and distribution of the article with the strict proviso that no changes or edits are made and the original work is properly cited (including links to both the formal publication through the relevant DOI and the license). See: https://creativecommons.org/ licenses/by-nc-nd/4.0/.

\section{References}

1. Bruni A, Stefani A, Perna M, et al. The role of postoperative radiotherapy for thymomas: a multicentric retrospective evaluation from three Italian centers and review of the literature. J Thorac Dis 2020;12:7518-30.

Cite this article as: Editorial Office. Erratum to the role of postoperative radiotherapy for thymomas: a multicentric retrospective evaluation from three Italian centers and review of the literature. J Thorac Dis 2021;13(3):2079. doi: 10.21037/jtd-2021-04 